\title{
Study on the surface-modification for nano-hydroxyapatite with 12-hydroxystearic acid and the reinforcing effect for poly(lactic-o-glycolide)
}

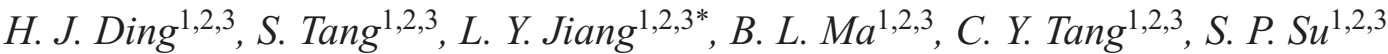 \\ ${ }^{1}$ National \& Local Joint Engineering Laboratory for New Petro-chemical Materials and Fine Utilization of Resources, \\ College of Chemistry and Chemical Engineering, Hunan Normal University, 410081 Changsha, PR China \\ ${ }^{2}$ Key Laboratory of Sustainable Resources Processing and Advanced Materials, College of Chemistry and Chemical \\ Engineering, Hunan Normal University, 410081 Changsha, PR China \\ ${ }^{3}$ Key Laboratory of Chemical Biology \& Traditional Chinese Medicine Research (Ministry of Education, China), College \\ of Chemistry and Chemical Engineering, Hunan Normal University, 410081 Changsha, PR China
}

Received 10 November 2019; accepted in revised form 18 January 2020

\begin{abstract}
In this paper, 12-hydroxystearic acid was used to modify the surface nano-hydroxyapatite( $n$-HA) by co-precipitation method or blending method. Fourier transformation infrared (FTIR), X-ray diffraction (XRD), intuitionistic dispersion, transmission electron microscope (TEM) and thermal gravimetric analysis (TGA) showed that the blending method confirmed 12-hydroxystearic acid was successfully grafted on the surface of $n$-HA, which endowed $n$-HA with better dispersion in hydrophobic solvents, and the dispersion was improved with the addition amount of 12-hydroxystearic acid. Correspondingly, it exhibited better improvement for poly (lactic-o-glycolide)(PLGA), owing to better interface adhesion in PLGA matrix and promotion crystallization by investigating the tensile strength, fracture morphology, polarized optical microscopy (POM), differential scanning calorimetry (DSC) and dynamic mechanical analysis (DMA) of the composites. Especially, the tensile strength was $23.81 \%$ higher than that of pure PLGA when $5 \mathrm{wt} \% n$-HA was added, suggesting the obtained $n$-HA was promising to improve the mechanical strength of PLGA. Moreover, in vitro cell culture, experimental results indicated that $n$-HA/PLGA composites displayed better cell biocompatibility. Taken together, these results demonstrated that the introduction of 12-hydroxystearic acid by blending method was a novel method to modify the surface of $n$-HA, which has a great potential to obtain ideal $n$-HA/PLGA composite as bone materials.
\end{abstract}

Keywords: polymer composites, nano-hydroxyapatite, surface modification

\section{Introduction}

Poly lactic(-co-glycolide) (PLGA), the most typical synthetic biodegradable copolymer, has superior controllable degradability by varying the ratio of L-lactide (L-LA) and glycolide acid (GA), and it has been approved by U.S. Food and Drug Administration (FDA) for clinical use, so it has received considerable attention in the biomedical field [1-4]. To further improve the bioactivity, nano-hydroxyapatite $\left[\mathrm{Ca}_{10}\left(\mathrm{PO}_{4}\right)_{6}(\mathrm{OH})_{2}, n\right.$-HA] has been systematically explored to prepare $n$-HA/PLGA composite, as it is a promising reinforcing filler for polymers and good osteoconductivity in bone materials [5-9], which was expected to possess good mechanical property and excellent cell adhesion [10-12], However, the weak interface adhesion between the hydrophilic $n$-HA particles and hydrophobic PLGA matrix allowed an easy agglomeration of the $n$-HA particles in the PLGA matrix, which causes poor mechanical properties of the composite $[13,14]$, so that it would severely 
restrict the application in bone materials. In consequence, a series of modification methods for $n$-HA were tried out to enhance the dispersion of $n$-HA [15-19]. But it is difficult to obtain ideal $n$-HA/PLGA composites with improved mechanical properties. In our previous study, many different surface modification methods for $n$-HA were studied, including the use of stearic acid. However, the surface modification effect was not very satisfactory [20-22]. Luckily, 12-hydroxystearic $\operatorname{acid}\left(\mathrm{CH}_{3}\left(\mathrm{CH}_{2}\right)_{5} \mathrm{CH}(\mathrm{OH})\left(\mathrm{CH}_{2}\right)_{10} \mathrm{COOH}\right)$ is a typical surfactant with a hydrophilic carboxyl group at one end and hydrophobic hydrocarbon chain at the other end, which has been widely used as an industrial raw material [23]. Additionally, the carboxyl group could react with $\mathrm{Ca}^{2+}$, so that 12-hydroxystearic acid would easily graft onto the surface of $n$-HA, correspondingly, the hydrocarbon chain of 12-hydroxystearic acid could be an ideal hydrophobic group to improve the dispersion in a hydrophobic solvent. Therefore, 12-hydroxystearic acid might have great potential to be used in surface-modification for $n$-HA.

Besides, metal ions can coordinate with 12-hydroxystearic acid to form a self-assembled film on the surface of the materials [24]. Therefore, if 12-hydroxystearic acid was blended with HA, the 12-hydroxystearic acid would be coordinated with $\mathrm{Ca}$ originated from HA. Meanwhile, if 12-hydroxystearic acid was added into the reactive system of $\mathrm{Ca}$ salt or $\mathrm{P}$ salt, then HA and 12-hydroxystearic acid would be co-precipitated. So the addition method of 12-hydroxystearic acid by different methods would affect the surface-modification for $n$-HA. On the other hand, the addition amount of 12-hydroxystearic acid was also an important factor for the surface-modification [25]. Besides, whether the surface-modified $n$-HA by12-hydroxystearic acid would enhance the mechanical property and the biocompatibility of PLGA, which was worth investigating.

Based on this, in this study, 12-hydroxystearic acid was chosen to modify the surface of $n$-HA with different addition amounts through co-precipitation method or blending method. The obtained $n$-HA was comprehensively evaluated by the Fourier transformation infrared (FTIR), X-ray diffraction (XRD), intuitionistic dispersion, transmission electron microscopy (TEM) and thermal gravimetric analysis (TGA) so that the reaction mechanism would be speculated. Then, the $n$-HA nanoparticles obtained by two different methods and pure $n$-HA were introduced into
PLGA with 5 or $10 \mathrm{wt} \%$, respectively. The properties of those composites were investigated by an electromechanical universal tester, polarized optical microscopy (POM), scanning electron microscopy (SEM), differential scanning calorimetry (DSC) and dynamic mechanical analysis (DMA). Finally, the in vitro cell biocompatibility of the new $n$-HA/PLGA composites with different surface-modified HA contents was carried out by methyl-thiazolyl-tetrazolium (MTT) assay and fluorescence microscopic observation. The main purpose of the study is to obtain an ideal surface-modification method for $n$-HA with 12-hydroxystearic acid by comparing the two different methods of co-precipitation method and blending method, aimed to develop $n$-HA/PLGA nanocomposite with superior mechanical property, which would be used as bone materials in the future.

\section{Materials and methods}

\subsection{Materials}

12-hydroxystearic acid was supplied by Xilong Chemical Co., Ltd., Shantou. PLGA was prepared in our laboratory, and the copolymer composition (LA: GA) was 95:05 (mol: mol) and $M_{\mathrm{w}}=3.6 \cdot 10^{5}$ $3.9 \cdot 10^{5} \cdot \mathrm{Na}_{3} \mathrm{PO}_{4} \cdot 12 \mathrm{H}_{2} \mathrm{O}(\mathrm{AR}), \mathrm{Ca}\left(\mathrm{NO}_{3}\right)_{2} \cdot 4 \mathrm{H}_{2} \mathrm{O}(\mathrm{AR})$, and $\mathrm{NaOH}$ (AR) were all bought from Tianjin Fengchuan Chemical Reagent Technologies Co., Ltd. Tianjin. All other reagents were of the analytical grade.

\subsection{Methods}

\subsubsection{Preparation of surface-modified $\boldsymbol{n}$-HA with 12-hydroxystearic acid}

A series of surface-modified $n$-HA nanoparticles with 12-hydroxystearic acid were prepared by coprecipitation method or solution blending methods as follows.

Co-precipitation method: Firstly, 12-hydroxystearic acid was dissolved in ethanol in a flask, and $\mathrm{Ca}\left(\mathrm{NO}_{3}\right)_{2} \cdot 4 \mathrm{H}_{2} \mathrm{O}$ dissolved in deionized water was slowly dripped into the above solution to react 2 hours with magnetic stirring at $70^{\circ} \mathrm{C}$. Then, $\mathrm{Na}_{3} \mathrm{PO}_{4} \cdot 12 \mathrm{H}_{2} \mathrm{O}$ dissolved in deionized water was added drop-wise in the mixture solution according to the $\mathrm{Ca} / \mathrm{P}$ molar ratio is 1.67. Subsequently, the mixture $\mathrm{pH}$ was adjusted to over 10 during the reaction for more than 4 hours at $70^{\circ} \mathrm{C}$, and then aged for 48 hours. The precipitates were washed with distilled water and ethanol several times before dried. According to the specific weight amount of 12-hydroxystearic acid, the products were 
noted as Co-HA (3 wt\%), Co-HA (10 wt $\%)$ and Co-HA (20 wt $\%)$, respectively.

Solution blending method: Pure $n$-HA was dispersed in the distilled water by ultrasonic treatment, in which 12-hydroxystearic acid dissolved in ethanol was added with the high rate stirring at $70^{\circ} \mathrm{C}$ for more than 4 hours, and the three samples were denoted as Bl-HA (3 wt \%), B1-HA (10 wt\%) and B1-HA (20 wt\%), respectively.

Besides, pure $n$-HA powder was synthesized according to the traditional precipitation method, noted as $n$-HA [26].

\subsubsection{Fabrication of $\boldsymbol{n}$-HA/PLGA composites}

Ten composites containing five different $n$-HA nanoparticles of unmodified $n$-HA, Co-HA $(10 \mathrm{wt} \%)$, Co-HA (20 wt $\%)$, Bl-HA (10 wt $\%)$, Bl-HA (20 wt\%) with the weight of 5 and $10 \mathrm{wt} \%$, respectively, were fabricated by solution mixing method. Firstly, the pre-calculated $n$-HA nanoparticles were dispersed in absolute ethanol and dichloromethane with ultrasonic treatment. Then, the above suspension of $n-\mathrm{HA}$ was slowly added into 4\% (w/v) PLGA dichloromethane solution, kept stirring for over 4 hours with magnetic stirring and ultrasonic treatment. Finally, the obtained mixtures were precipitated by slowly adding the mixtures solution into a large amount of absolute ethanol with the high-speed stirring, and washed with absolute ethanol, then the products were dried in a vacuum oven at $40{ }^{\circ} \mathrm{C}$ until they were completely dried, which were separately named as $n-\mathrm{HA} /$ PLGA-5 wt $\%$, Co-HA (10 wt \%)/PLGA-5 wt $\%$, Co-HA $(20 \mathrm{wt} \%) /$ PLGA-5 wt $\%$, Bl-HA (10 wt $\%) /$ PLGA-5 wt \%, B1-HA (20 wt\%)/PLGA-5 wt $\%$, $n$-HA/PLGA-10 $\mathrm{wt} \%$, Co-HA $(10 \mathrm{wt} \%) /$ PLGA$10 \mathrm{wt} \%$, Co-HA (20 wt $\%) /$ PLGA-10 wt $\%$, Bl-HA $(10 \mathrm{wt} \%) / \mathrm{PLGA}-10 \mathrm{wt} \%$, and B1-HA $(20 \mathrm{wt} \%) /$ PLGA-10 wt $\%$.

\subsubsection{Characterization of surface-modified n-HA}

To verify the 12-hydroxystearic acid grafting reaction happened, the IR analysis of all $n$-HA samples were studied by a Thermo Nicolet 670 spectrometer in $\mathrm{KBr}$ disks. The spectra range of scanning was over $4000-500 \mathrm{~cm}^{-1}$ with a spectral resolution of $4 \mathrm{~cm}^{-1}$. X-ray diffraction (XRD, Bruker AXS, Germany) analyses of all $n$-HA samples were performed in the following conditions: $\mathrm{Cu} \mathrm{K} \alpha$ radiation $(\lambda=1.5405 \AA)$, $10-70^{\circ}$ of $2 \theta$, step size $0.01^{\circ}$, scan speed $0.02^{\circ} \cdot \mathrm{s}^{-1}$.
Besides, the crystallinity, the mean crystal sizes and the crystal cell parameters of samples were calculated by software Jade 5.0 and Scherrer's formula [27]. The dispersion of all $n$-HA samples was observed by intuitionistic dispersion pictures, in which a small amount of sample was dispersed in dichloromethane by the same ultrasonication condition with the power of 50 watts and the time of $10 \mathrm{~min}$, and the dispersion pictures of samples' suspension were taken by a conventional camera at different time periods.

TGA (STA 409PC, Netzsch, Germany) was used to investigate the amount of grafting amount of 12-hydroxystearic acid on the $n$-HA samples. The powders of $n$-HA, Co-HA (20 wt $\%$ ), and Bl-HA (20 wt $\%$ ) were heated up to $800^{\circ} \mathrm{C}$, at a heating rate of $10^{\circ} \mathrm{C} / \mathrm{min}$ in $\mathrm{N}_{2}$ conditions. The grafting ratios were calculated with the weight loss percentage during the heating process.

The morphology, size of pure $n-\mathrm{HA}$, Co-HA $(20 \mathrm{wt} \%)$, Bl-HA (20 wt $\%$ ) were investigated by transmission electron microscopy (TEM, JME-2100, JEOL, Japan) at an acceleration voltage of $200 \mathrm{kV}$. The samples were dispersed in dichloromethane by the ultrasonication, respectively and one drop of the suspension was dropped onto a TEM grid covered with carbon film. The TEM observation was performed after the solvent was naturally volatilized at room temperature completely.

\subsubsection{Properties of $\boldsymbol{n}$-HA/PLGA composites}

The tensile strengths of PLGA and the PLGA-based composites were measured by electromechanical universal testing machine (WDW-20, China). The samples were hot-pressed into the size of $0.5 \mathrm{~mm} \times$ $4 \mathrm{~mm} \times 60 \mathrm{~mm}$ with a platen vulcanizing heater at $180^{\circ} \mathrm{C}$, which were measured at a speed of $5 \mathrm{~mm} / \mathrm{min}$ at room temperature with the relative humidity of $60 \%$. The mean value of five parallel samples of each specimen was given.

The fracture surfaces of the composites $n$-HA/ PLGA-5 wt $\%$, Co-HA (20 wt $\%) /$ PLGA-5 wt $\%$, B1-HA $\quad(20 \mathrm{wt} \%) /$ PLGA-5 $\mathrm{wt} \%, \quad n$-HA/PLGA$10 \mathrm{wt} \%$, Co-HA (20 wt $\%) /$ PLGA-10 wt $\%$, Bl-HA (20 wt $\%) / P L G A-10 \mathrm{wt} \%$ were observed by a scanning electron microscopy (SEM, S-450, FEM, Chech) at an acceleration voltage of $20 \mathrm{kV}$ after a gold layer was uniformly sputtered on all samples.

The spherulitic morphology and its growth process were observed by polarized optical microscopy (POM) equipped with a hot stage (model XPV-880E). 
The samples of PLGA and the PLGA-based composites with $5 \mathrm{wt} \%$ surface-modified HA or unmodified $n$-HA were heated to melting at $210^{\circ} \mathrm{C}$ with $10^{\circ} \mathrm{C} / \mathrm{min}$ heating rate and then cooled to crystallization temperature of $120^{\circ} \mathrm{C}$ with $30^{\circ} \mathrm{C} / \mathrm{min}$ cooling rate, separately. Finally, the isothermal crystallization behavior was observed by a polarizing microscope at different time periods.

Differential scanning calorimetric (DSC) analyzer (DSC 200 F3, Netzsch, Germany) was used to measure the thermal properties of PLGA, $n$-HA/PLGA, Co-HA (20 wt $\%) /$ PLGA-5 wt $\%$, Bl-HA $(20 \mathrm{wt} \%) /$ PLGA-5 wt $\%$ and Bl-HA (20 wt $\%$ )/PLGA-10 $w t \%$ composites. The sample was heated from room temperature to $190^{\circ} \mathrm{C}$ with $10^{\circ} \mathrm{C} / \mathrm{min}$ heating rate and kept constant at the temperature for 5 minutes under $\mathrm{N}_{2}$ condition, then cooled to $20^{\circ} \mathrm{C}$ with the cooling rate of $10^{\circ} \mathrm{C} / \mathrm{min}$ under $\mathrm{N}_{2}$ condition. After all previous thermal history was erased, the sample was heated again to $190^{\circ} \mathrm{C}$ at the same heating rate under $\mathrm{N}_{2}$ condition. The crystallinity $\left(X_{\mathrm{c}}\right)$ was calculated by the following formula of Equation (1):

$$
X_{\mathrm{c}}=\frac{\Delta H_{\mathrm{m}}}{\omega \cdot \Delta H_{\mathrm{m}, 100 \%}}
$$

where the $\Delta H_{\mathrm{m}}$ and $\Delta H_{\mathrm{m}, 100 \%}$ in the above formula were the melting enthalpy and the theoretical enthalpy of completely crystalline poly(L-lactic acid), respectively, and the theoretical enthalpy value was 93.7 J/g. And the $\omega$ was the mass fraction of PLGA in the composite [28].

The storage moduli $\left(E^{\prime}\right)$ and loss factor $(\tan \delta)$ of PLGA and PLGA-based composites with $n$-HA, Co-HA $(20 \mathrm{wt} \%)$ or Bl-HA $(20 \mathrm{wt} \%)$ in the weight ratio of $5 \mathrm{wt} \%$ were measured in tensile mode by a dynamic mechanical analyzer (DMA 242E, Netzsch, Germany). The composite strips with the size of $0.2 \mathrm{~mm} \times 4 \mathrm{~mm} \times 30 \mathrm{~mm}$ were tested in the temperature range from 25 to $90^{\circ} \mathrm{C}$, and the constant frequency was $2.5 \mathrm{~Hz}$, the heating rate was $3^{\circ} \mathrm{C} / \mathrm{min}$.

The cell biocompatibility of PLGA, $n$-HA/PLGA and two Bl-HA/PLGA composites containing 5 and $10 \%$ BL-HA were investigated by bone mesenchymal stem cells (BMSC), and BMSC was extracted from a week-old SD rat neonatal by the sequential enzymatic digestive process. The Dulbecco's Modified Eagle medium (D-MEM) was contained, containing 10\% fetal bovine serum (FBS), $200 \mathrm{mg} / \mathrm{ml}$ penicillin, and $200 \mathrm{mg} / \mathrm{ml}$ streptomycin. The third passage BMSCs were removed into the culture medium with osteogenic reagents [29]. The samples with the size of $\varnothing 6 \times 0.2 \mathrm{~mm}$ were cleaned with $75 \%$ ethanol solution and sterilized under an ultraviolet lamp. The treated samples with the cell density of 8000 every well were placed in a 96-well plate, undisturbed in an incubator for $3 \mathrm{~h}$, then an additional $1 \mathrm{ml}$ of culture medium was added.

Cell proliferation was evaluated by MTT (3-\{4,5-dimethylthiazol-2yl\}-2,5-diphenyl-2H-tetrazoliumbromide) assay [30]. The medium in the cell-seeded nanoparticles were discarded after designating 1, 2 and 3 days, and $100 \mu 1$ MTT solution with $3 \mathrm{mg} / \mathrm{ml}$ was added, incubated for the last $4 \mathrm{~h}$ at $37^{\circ} \mathrm{C}$ in an air atmosphere containing $5 \% \mathrm{CO}_{2}$, and $100 \mu \mathrm{l}$ dimethyl sulphoxide (DMSO) was added to dissolve the formazan crystals. Then the $200 \mu 1$ purple solution was absorbed and transferred into a new 96-well plate, the optical density (OD) values of solution were measured in a microplate reader (Synergy HTX, BIOTEK, USA) at $492 \mathrm{~nm}$.

The adhesion and proliferation of BMSCs on the surface of composites were more intuitively given by the fluorescent pictures. The samples were taken out after incubation for 1, 2 and 3 days, dyed for 10 minutes and rinsed with phosphate buffer solution (PBS) twice, $1 \mathrm{ml}$ acridine orange (AO) solution $(0.1 \mathrm{mg} / \mathrm{ml})$ was added to the surface of the samples, then rinsed with PBS twice again, and the fluorescence microscope (Axioskop 2, ZEISS, Germany) was used to observe the morphology and growth of cells.

\section{Results and discussion}

\subsection{Characterization of surface-modified $n$-HA}

\subsubsection{IR analysis}

FT-IR spectra of the samples of pure $n$-HA and all surface-modified $n$-HA were shown in Figure 1. Some of the main absorption peaks were identified, including $\mathrm{PO}_{4}{ }^{3-}$ groups vibration bands (1095.1, $\left.1041.3,962.3,874.2,604.1,563.7 \mathrm{~cm}^{-1}\right), \mathrm{CO}_{3}{ }^{2-}$ groups vibration $\left(1417.2 \mathrm{~cm}^{-1}\right)$ and the $\mathrm{H}$-bonded associated with $-\mathrm{OH}$ groups $\left(3566.8 \mathrm{~cm}^{-1}\right)$, and these results were in accordance with that of $n$-HA in literature [31]. Besides, the stretching modes of $\mathrm{H}_{2} \mathrm{O}\left(3404.9\right.$ and $\left.1637.8 \mathrm{~cm}^{-1}\right)$ were found in each sample. However, for the samples of HA surfacemodified with 12-hydroxystearic acid, the peaks of $2922.5,2851.2,1466.7$ and $1384.7 \mathrm{~cm}^{-1}$ were found, which were assigned to the stretching vibration and bending vibration of $\mathrm{C}-\mathrm{H}$, indicating that 


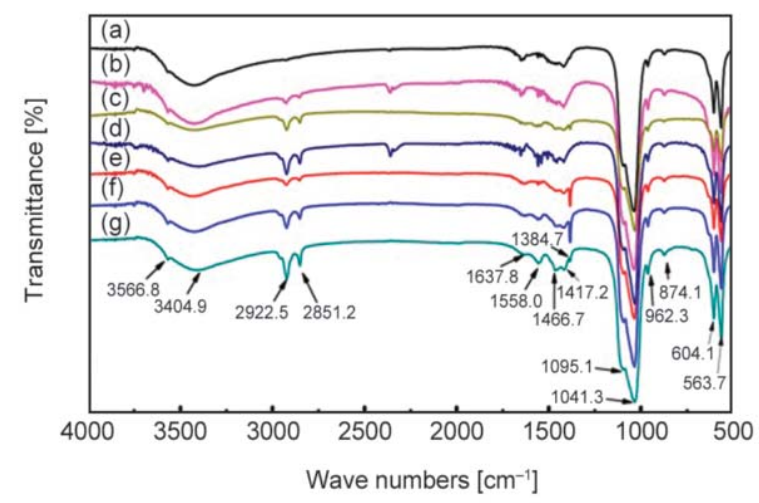

Figure 1. FTIR spectra of samples. (a) HA, (b) Co-HA $(3 \mathrm{wt} \%), \quad$ (c) $\mathrm{Co}-\mathrm{HA} \quad(10 \mathrm{wt} \%), \quad$ (d) $\mathrm{Co}-\mathrm{HA}$ $(20 \mathrm{wt} \%), \quad$ (e) Bl-HA $\quad(3 \mathrm{wt} \%), \quad$ (f) Bl-HA (10 wt $\%)$, (g) Bl-HA (20 wt \%).

12-hydroxystearic acid was grafted onto HA nanoparticles. Additionally, the characteristic peaks of $-\mathrm{COO}^{-}$also appeared at $1558.0 \mathrm{~cm}^{-1}$, which further demonstrated the formation of 12-hydroxystearic acid-HA nanoparticles [32], and there was no obvious difference between the Co-HA and Bl-HA, except for the peak intensity difference. Moreover, the more 12-hydroxystearic acid amount was added, a stronger the new peak was found, meaning the higher grafting rate was obtained on the surface of HA.

\subsubsection{XRD investigation}

Figure 2 gave XRD patterns of all HA samples. They displayed characteristic intense peaks at $25.87^{\circ}(002), 31.81^{\circ}(211), 32.17^{\circ}(112), 32.86^{\circ}(300)$, $34.04^{\circ}(202), 39.85^{\circ}(310), 46.74^{\circ}(222), 49.50^{\circ}(213)$ and $53.24^{\circ}(004)$ without the other diffraction pattern phases being detected, consisting with the crystalline nature of pure $n$-HA(JCPDS 09-0432) [33]. By comparison, we could see that the characteristic peaks of Co-HA $(20 \mathrm{wt} \%)$ sample with the addition amount of 12-hydroxystearic acid of $20 \mathrm{wt} \%$ became flatter and its intensity became weaker, while the peaks of Co-HA (10 wt $\%)$ sample were no obvious change, compared with pure $n$-HA, which was resulted from

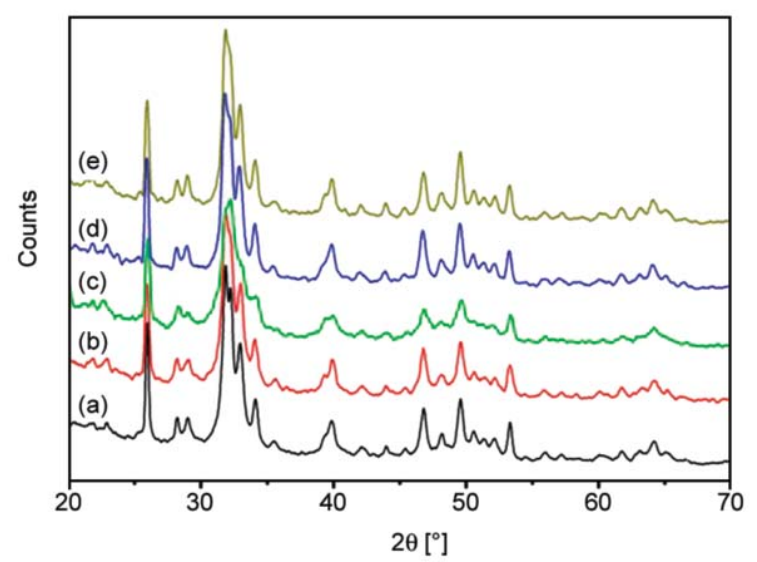

Figure 2. XRD spectra of samples. (a) HA, (b) Co-HA $(10 \mathrm{wt} \%), \quad$ (c) $\mathrm{Co}-\mathrm{HA} \quad(20 \mathrm{wt} \%), \quad$ (d) B1-HA (10 wt $\%)$, (e) Bl-HA (20 wt $\%)$.

the fact that the more 12-hydroxystearic acid would distort the lattice of HA and decreased the crystallinity obviously. However, for Bl-HA (10 wt \%) and Bl-HA(20 wt\%) samples, their characteristic peaks had no obvious decrease. To further discuss the crystal structural difference of all $n$-HA samples, the degree of crystallinity and the mean crystallite sizes, cell parameters of samples were obtained by the Scherrer's formula and software Jade 6.0, which were listed in Table 1. From the data in the table, it could be found that the degree of crystallinity and the mean crystallite size of Co-HA $(10 \mathrm{wt} \%)$ and Co-HA(20 wt $\%)$ samples obtained by the co-precipitation method decreased and the cell parameters also decreased correspondingly. While the Bl-HA (10 wt\%) and Bl-HA (20 wt\%) samples had no obvious change. The result showed that the co-precipitation method had a great influence on HA particles, which could make 12-hydroxystearic acid enter the HA lattice and changed the crystal structure, to decrease the crystallinity of $n$-HA, and the change was more obvious with the increasing of the addition amount of 12-hydroxystearic acid. However, for the blending method, most of the 12-hydroxystearic acid could only be grafted onto the surface of HA.

Table. 1. Crystallite sizes and crystallinity of samples.

\begin{tabular}{|c|c|c|c|c|c|c|}
\hline \multirow[t]{2}{*}{ Samples } & \multirow{2}{*}{$\begin{array}{c}\text { Degree of } \\
\text { crystallinity } \\
{[\%]}\end{array}$} & \multicolumn{2}{|c|}{$\begin{array}{c}\text { Mean crystallite size } \\
{[\mathrm{nm}]}\end{array}$} & \multicolumn{3}{|c|}{$\begin{array}{c}\text { Cell parameters } \\
{[\AA \AA]}\end{array}$} \\
\hline & & $c$ axis & $a$ axis & $a$ & b & $c$ \\
\hline Pure $n$-HA & 82.14 & 31.241 & 11.406 & 9.4630 & 9.4630 & 6.9227 \\
\hline Co-HA (10 wt $\%)$ & 76.18 & 26.782 & 9.783 & 9.4101 & 9.4101 & 6.8761 \\
\hline Co-HA $(20$ wt\% $\%)$ & 73.52 & 22.147 & 8.294 & 9.3822 & 9.382 & 6.8600 \\
\hline Bl-HA (10 wt $\%)$ & 80.12 & 29.527 & 10.907 & 9.4342 & 9.4342 & 6.9092 \\
\hline Bl-HA (20 wt\%) & 80.33 & 29.421 & 10.583 & 9.4400 & 9.4400 & 6.8730 \\
\hline
\end{tabular}




\subsubsection{Dispersion effect}

Figure 3 displayed the intuitional dispersion photos of all the samples. The samples were dispersed in dichloromethane by the same ultrasonic treatment, and the different suspensions were photographed by a conventional camera at different time periods after ultrasonication. From the photos, it could be found that the dispersion of surface-modified HA nanoparticles obviously got better and better with the increasing amount of 12-hydroxystearic acid, compared to pure $n$-HA, and the results were in good consistent with the FT-IR spectra. Besides, it must also be mentioned that the dispersion of Bl-HA nanoparticles displayed better than that of Co-HA nanoparticles. The possible reason was that the blending method caused more 12-hydroxystearic acid to be surface-grafted on the surface of $n$-HA, compared to the co-precipitation method.

\subsubsection{TGA}

The TGA analysis for pure $n$-HA, Bl-HA (20 wt $\%$ ) and Co-HA (20 wt\%) samples was presented in Figure 4. From the TGA curves, during the course of heating, it can be seen that the samples of pure $n$-HA, Bl-HA (20 wt $\%)$ and Co-HA (20 wt $\%)$ had different weight losses of 4.00, 11.63 , and $22.15 \%$, respectively. So the grafted amounts of 12-hydroxystearic acid in the $n$-HA particles can be calculated roughly by the following equation: The grafting amounts = weight loss $\%$ (Bl-HA or Co-HA)-weight loss $\%(n-\mathrm{HA})$. And the corresponding data are 7.63

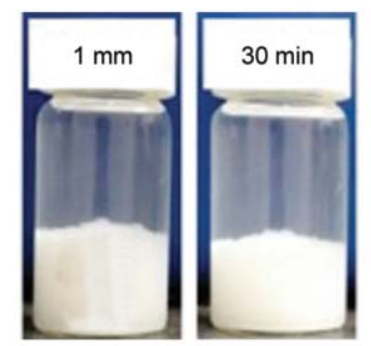

a)

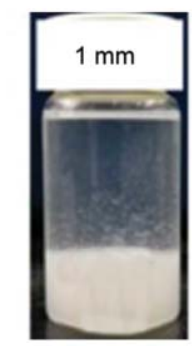

b)

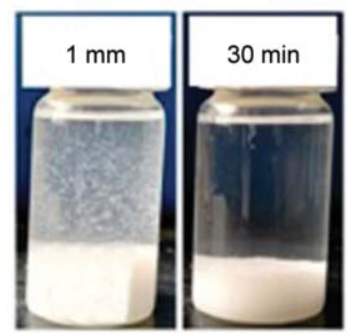

e)
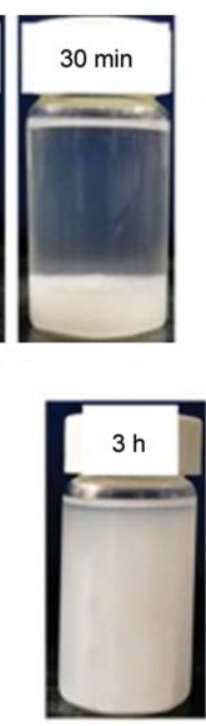

f)

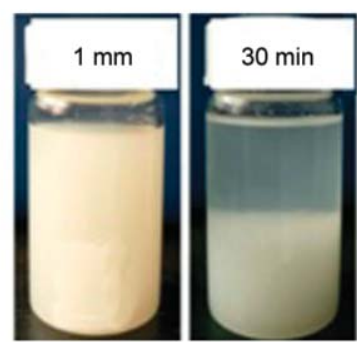

c)

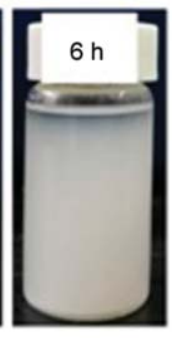

Figure 3. The intuitionistic of samples.(a) HA, (b) Co-HA (3 wt\%), (c) Co-HA (10 wt\%), (d) Co-HA (20 wt\%), (e) Bl-HA

(3 wt\%), (f) Bl-HA (10 wt\%), (g) Bl-HA (20 wt \%).

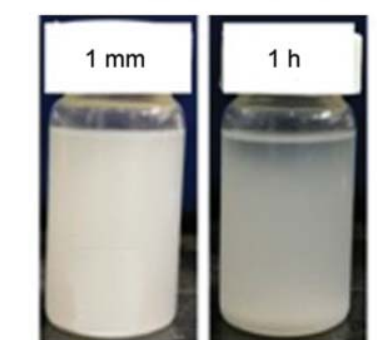

d)

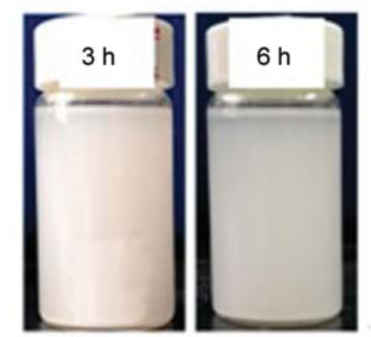

g) and $18.15 \%$ for the samples Bl-HA (20 wt $\%)$ and Co-HA (20 wt $\%)$, respectively. Obviously, it is further proved that $n$-HA was successfuly modified by 12-hydroxystearic acid quantitatively, and the total grafting amount of Co-HA (20 wt $\%)$ was higher than that Bl-HA (20 wt \%). The main difference in weight loss was attributed to the varying amounts of in the $n$-HA particles, which showed that the co-precipitation method was more conducive to graft 12-hydroxystearic acid than the blending method. However, at lower temperature, Bl-HA (20 wt $\%$ ) had a more weight loss than Co-HA (20 wt $\%)$, while at higher temperature of $320 \sim 500^{\circ} \mathrm{C}$, Co-HA $(20 \mathrm{wt} \%)$ had more outstanding weight loss than Bl-HA (20 wt $\%$ ), and the weight loss came from the decompose of the12-hydroxystearic acid, which further demonstrated that more 12-hydroxystearic acid was grafted on the surface of B1-HA, which would bring about better dispersion than Co-HA (20 wt\%), while for Co-HA, most of the 12-hydroxystearic acid was incorporated into lattice of $n$-HA effectively, so it displayed poor dispersion.

\subsubsection{TEM}

To further demonstrate the difference between the two surface-modification methods of co-precipitation and blending method, the TEM images of pure $n$-HA and two surface-modified HA with $20 \mathrm{wt} \%$ 12-hydroxystearic acid were shown in Figure 4. From the pictures, we could see that the morphology and size of the Bl-HA (20 wt\%) did not change, 


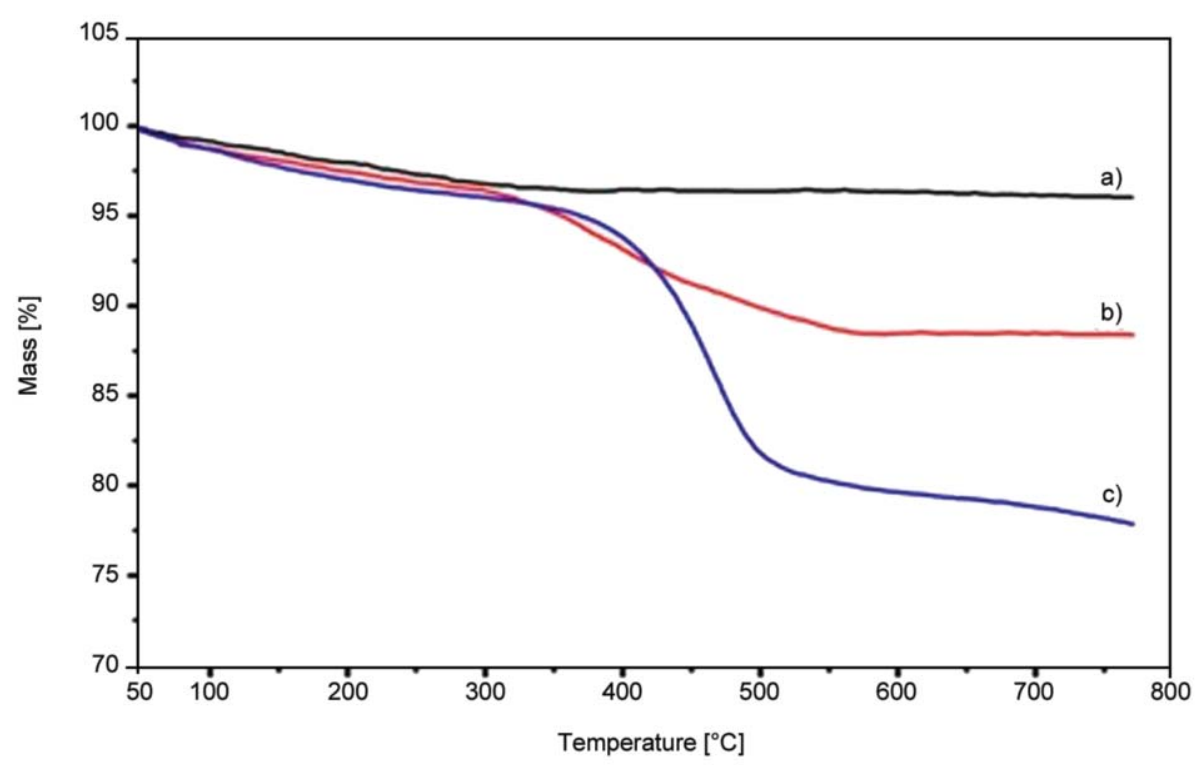

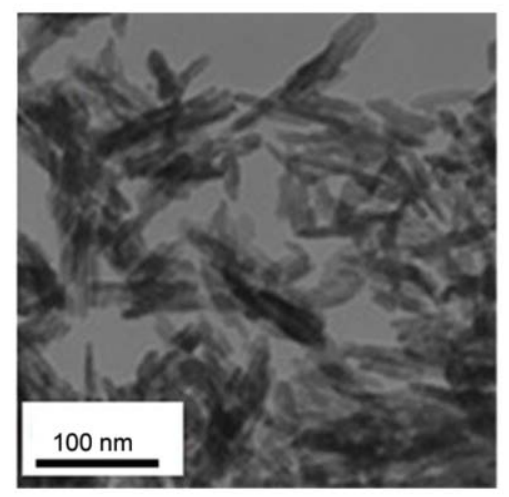

a)

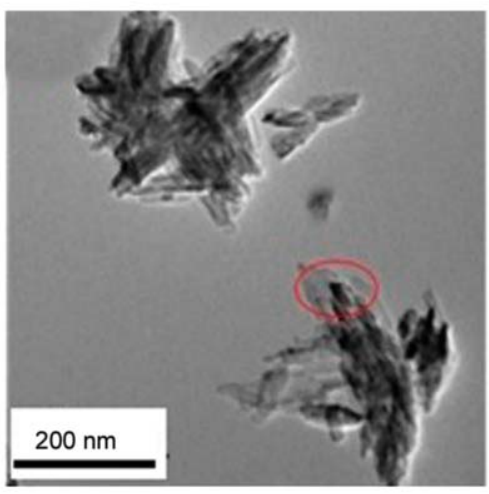

b)

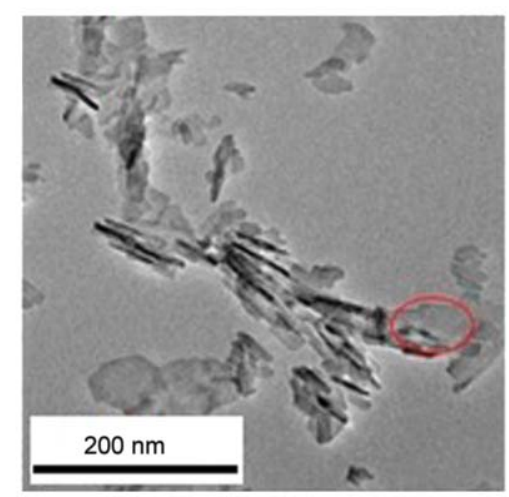

c)

Figure 4. TGA curves of $n$-HA and $n$-HA modified by different methods. (a) HA, (b) Bl-HA (20 wt $\%$ ), (c) Co-HA (20 wt $\%$ ).

compared with $n$-HA. They were all needle-like with a size of $110-130 \mathrm{~nm}$ in length and $10-20 \mathrm{~nm}$ in width. However, the morphology and size of the Co-HA (20 wt $\%)$ sample had a big change, it looked like whiskers with a size of $60-80 \mathrm{~nm}$ in length and 6-8 $\mathrm{nm}$ in width. On the other hand, it could be found that $n$-HA and 12-hydroxystearic acid were both interconnected well by two different methods (seen in the red circles). However, for Co-HA (20 wt $\%$ ) sample, the $n$-HA particles seemed to separate from 12-hydroxystearic acid, and $n$-HA particles grew on the surface of 12-hydroxystearic acid, which was caused by the fact that 12-hydroxystearic acid matrix precipitated continuously before the growth of HA crystal, because of the addition of poor solvents (the aqueous solution of $\mathrm{Ca}\left(\mathrm{NO}_{3}\right)_{2} \cdot 4 \mathrm{H} 2 \mathrm{O}$ and $\left.\mathrm{Na}_{3} \mathrm{PO}_{4} \cdot 12 \mathrm{H}_{2} \mathrm{O}\right)$.

Based on the above results, the modification reaction with 12-hydroxystearic acid for $n$-HA by two different methods could be described as shown in Figure 5. First, for the blending method, the Ca carboxylate bond was formed by $\mathrm{Ca}^{2+}$ on the surface of $n-\mathrm{HA}$ and carboxyl of 12-hydroxystearic acid (Equation (a) in Figure 5), then 12-hydroxystearic acid was successfully grafted onto the surface of $n$-HA. However, for the co-precipitation method, owing to the addition of poor solvents, the surface of the 12-hydroxystearic acid particles precipitated from mixed solvents bound a large amount of $\mathrm{Ca}^{2+}$ to form Ca carboxylate bonds, then, with the addition of phosphate ions and hydroxide ions, HA crystals grew on the surface of 12-hydroxystearic acid continually (Equation (b) in Figure 5). That is to say, most of the 12-hydroxystearic acid was incorporated into HA. This also explained why Co-HA (20 wt $\%)$ sample had a higher total grafting rate, but its dispersion was not well.

\subsection{Effect of surface-modified $\boldsymbol{n}$-HA on the mechanical property of PLGA}

\subsubsection{Tensile strength}

In order to study the reinforce effect of four surfacemodified $n$-HA nanoparticles of Co-HA (10 wt $\%)$, Co-HA (20 wt $\%)$, Bl-HA (20 wt\%) and Bl-HA $(20 \mathrm{wt} \%)$ for PLGA, the tensile strength of pure 


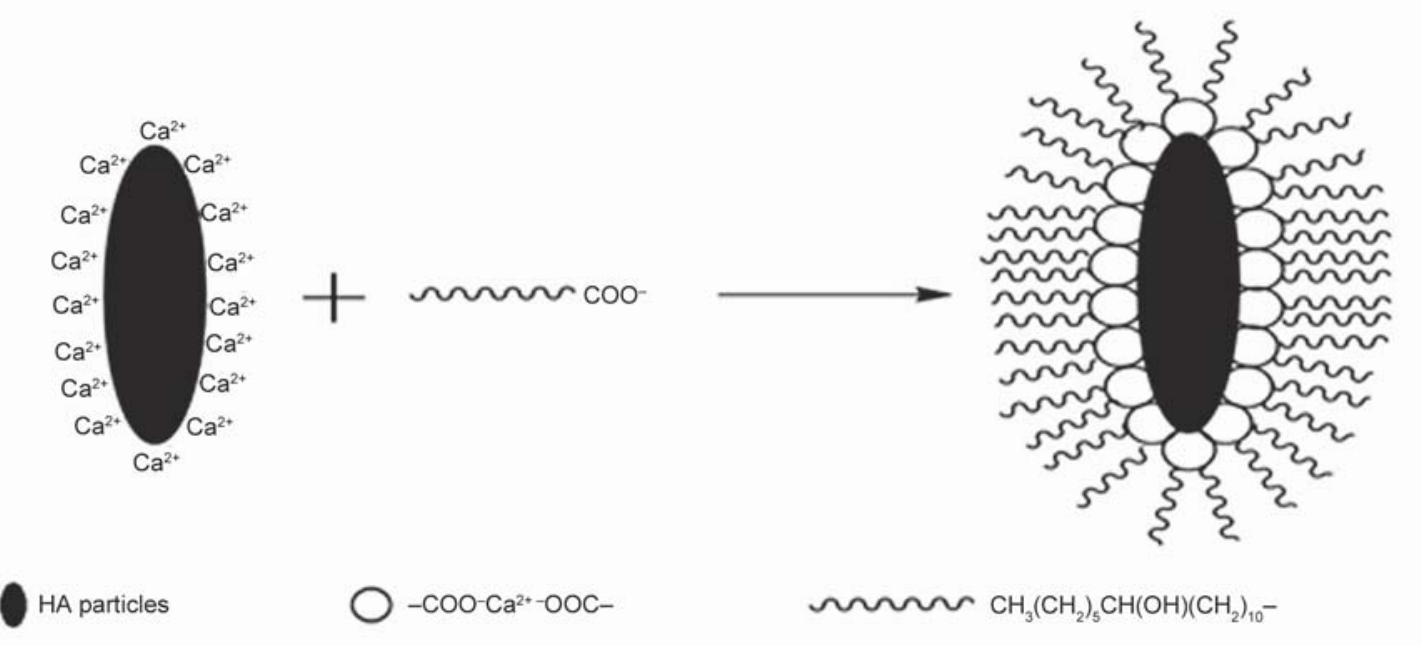

a)

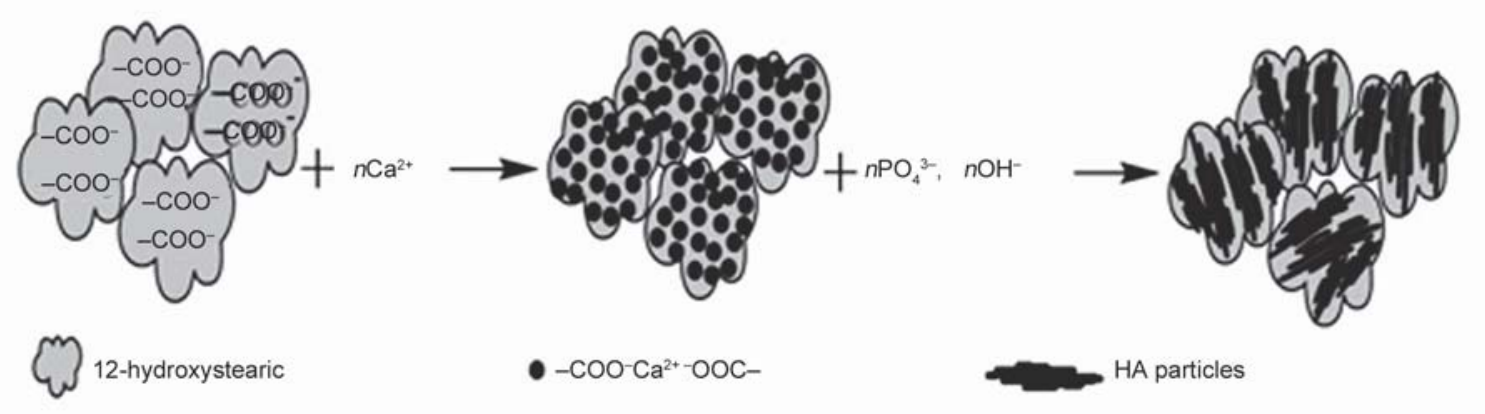

b)

Figure 5. Illustration of the surface modification of $n$-HA. (a) Blending method, (b) Co-precipitation method.

PLGA and ten HA/PLGA composites with 5 or $10 \mathrm{wt} \%$ nanoparticles were given in Figure 6. Obviously, it could be found that the tensile strength of HA/PLGA composites with $5 \mathrm{wt} \%$ addition content significantly increased, compared with PLGA. Especially, when $5 \mathrm{wt} \%$ Bl-HA (20 wt $\%$ ) was added, the tensile strength of the composite was over $23 \%$ higher than that of pure PLGA. However, when $10 \mathrm{wt} \%$ nanoparticles were added, the tensile strength of all the composites had no enhancement effect,

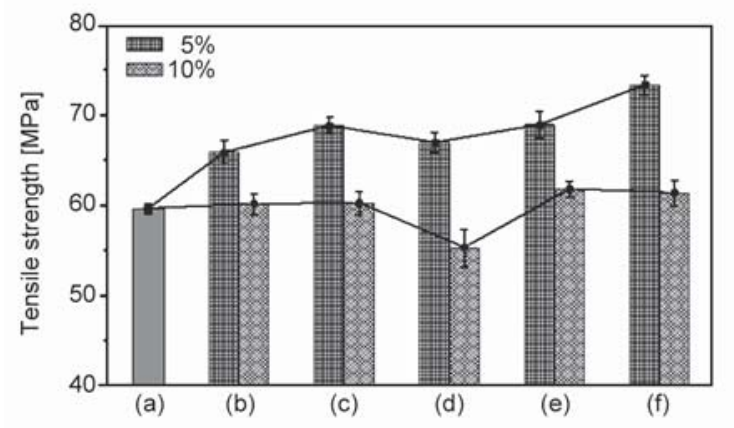

Figure 6. Tensile strength of pure PLGA and the three composites. (a) pure PLGA, (b) $n$-HA/PLGA, (c) CoHA (10 wt $\%$ )/PLGA, (d) Co-HA (20 wt $\%) /$ PLGA, (e) Bl-HA (10 wt\%)/PLGA, (f) Bl-HA (20 wt \%)/ PLGA. even decreased markedly for the Co-HA/PLGA $(10 \mathrm{wt} \%)$ composite. The main reason may be ascribed to the fact the blending method was more conducive to obtain much 12-hydroxystearic acid on the surface of $n$-HA, which might improve the interface adhesion between B1-HA nanoparticles and PLGA polymer, while the Co-HA nanoparticles obtained by the co-precipitation method contained higher graft amount of 12-hydroxystearic acid due to the intercalation, but these organic components was not completely grafted on the surface of $n$-HA, so it did not improve the dispersion of particles, on the contrary, it reduced the enhancement of the particles themselves as a rigid particle filler.

\subsubsection{SEM observation}

To understand the relation between the tensile strength of the composites and the dispersion of the surfacemodified HA particles in PLGA matrix, the fractured surfaces of the six $n$-HA/PLGA composites were observed by SEM, which was shown in Figure 7. From the photographs, we could see that there was a serious agglomeration in the PLGA matrix for the unmodified $n$-HA nanoparticles, when the filler amount 


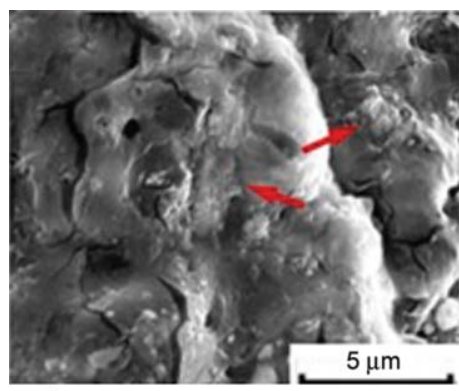

a)

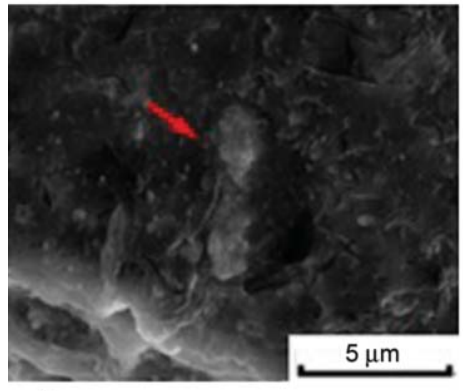

d)

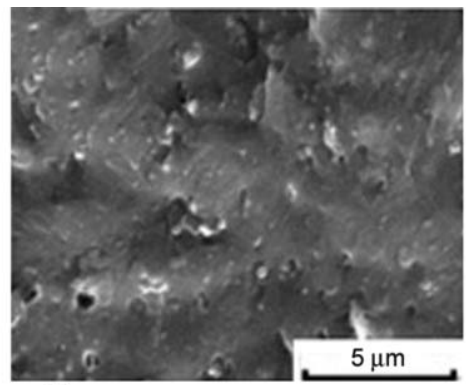

b)

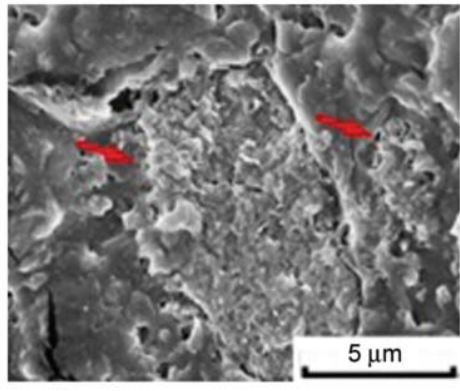

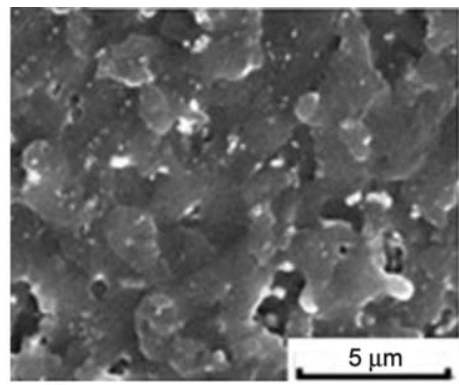

c)

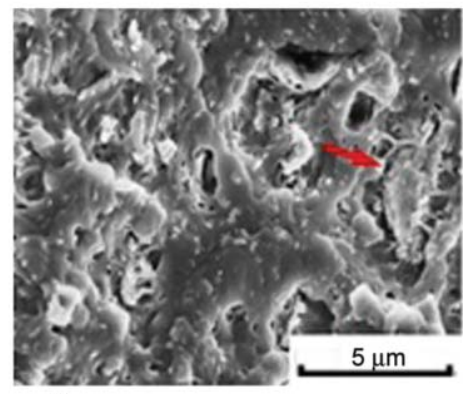

d)

Figure 7. SEM micrographs of pure PLGA and the three composites. (a) $n$-HA/PLGA- $5 \mathrm{wt} \%$, (b) Co-HA (20 wt $\%$ )/PLGA$5 \mathrm{wt} \%$, (c) Bl-HA $(20 \mathrm{wt} \%) /$ PLGA-5 wt $\%$, (d) $n$-HA/PLGA-10 wt $\%$, (e) Co-HA (20 wt $\%$ )/PLGA-10 wt $\%$, (f) BlHA $(20 \mathrm{wt} \%) /$ PLGA-10 wt $\%$.

was $5 \mathrm{wt} \%$ (shown in Figure 7a). On the contrary, for the surface-modified $n$-HA nanoparticles, there were no similar phenomena in fractured surface for Co-HA/PLGA- $5 \mathrm{wt} \%$ and Bl-HA/PLGA- $5 \mathrm{wt} \%$ composites (shown in Figure $7 \mathrm{~b}$ and $7 \mathrm{c}$ ), illustrating that the interfacial bonding was evidently improved between the two kinds of surface-modified $n$-HA nanoparticles and the PLGA matrix. More importantly, the results were obviously better than that of the $n$-HA surface-modified by stearic acid [21], and the reason was attributed to the structural difference of 12-hydroxystearic acid and stearic acid, and the excess hydroxyl of 12-hydroxystearic acid would be more advantageous to grafted on the $n$-HA, which correspondingly would improve the interfacial bonding. Therefore, it could be concluded that the $n$-HA nanoparticles modified by the co-precipitation method or blending method had a better dispersion effect than $n$-HA in PLGA matrix. However, when the filler amount was increased to $10 \mathrm{wt} \%$, the compatibility and dispersion decreased rapidly, and it was inevitable that there existed agglomeration for the three composites. However, the agglomeration size of Bl-HA (20 wt $\%$ ) was by far smaller than Co-HA (20 wt $\%$ ) in PLGA matrix (shown in Figure 7e and 7f), which was one of the reasons for the mechanical property difference [34].

\subsubsection{POM observation}

To further understand the crystalline nucleation effect of the surface-modified $n$-HA nanoparticles on the mechanical behavior of the composites, the isothermal crystallization process of pure PLGA and five $n$-HA/PLGA composites at $120^{\circ} \mathrm{C}$ were taken at different time periods. In Figure 8, the spherulite morphologies of all samples did not display remarkable differences, but their sizes and numbers of spherulites were different. It could be seen that the number of spherulites formed of pure PLGA was very seldom at the early stage of crystallization, and the subsequent growth process of the spherulites was also extremely slow. However, after the different $n$-HA nanoparticles were added, the numbers of spherulites of the Co-HA/PLGA or B1-HA/PLGA composites got more, and the crystallization time of growing to full screen became shorter, compared to the $n$-HA/PLGA composite and pure PLGA, which was caused by the reason that surface-modified HA nanoparticles played a role as heterogeneous nucleating agents in the crystallization process. It could be concluded that the promotion crystalline rate was in accord with the order as Bl-HA $(20 \mathrm{wt} \%)>\mathrm{Bl}-\mathrm{HA}$ $(10 \mathrm{wt} \%)>$ Co-HA $(20 \mathrm{wt} \%)>$ Co-HA $(10 \mathrm{wt} \%)>$ $n$-HA, which indicated that the heterogeneous nucleation of modified nanoparticles by the blending 


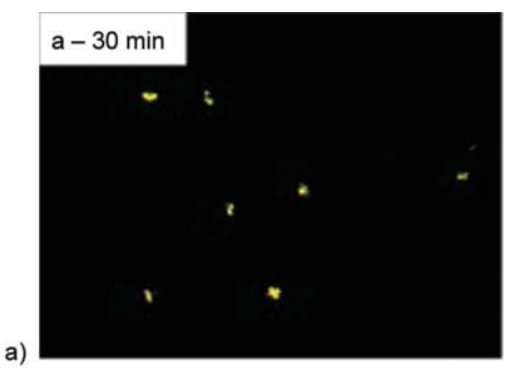

b)
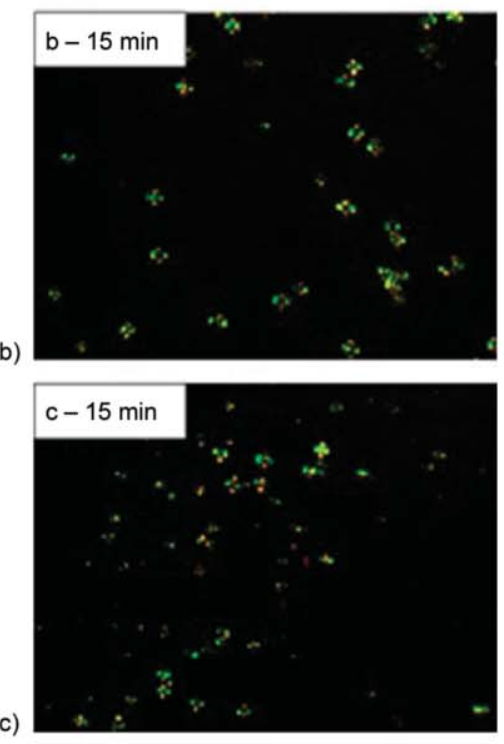

d)
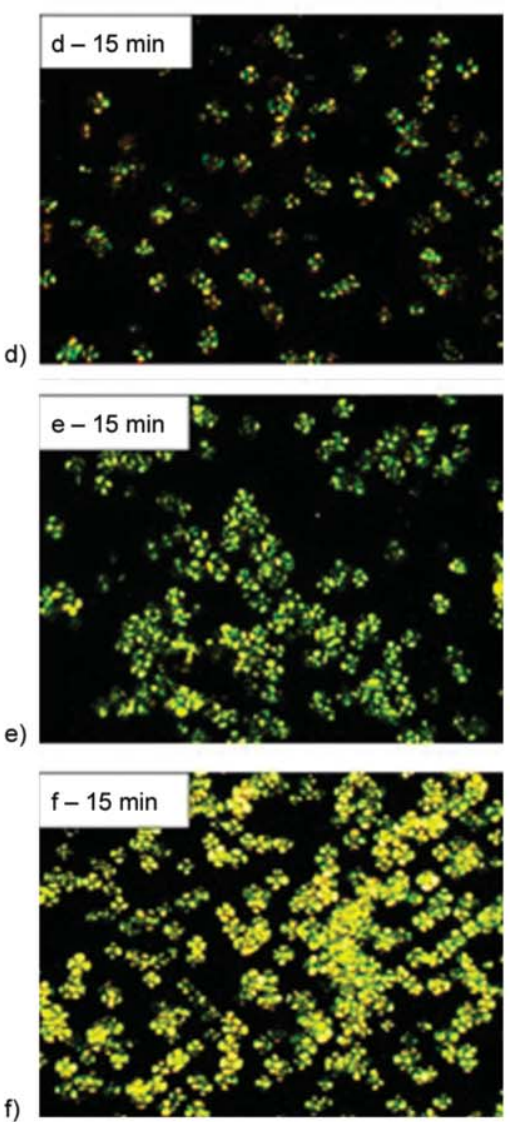
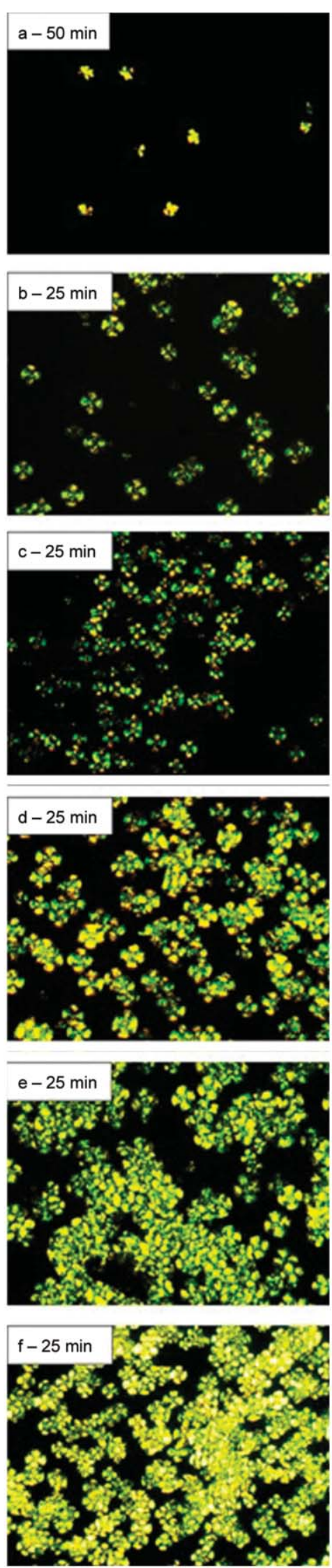
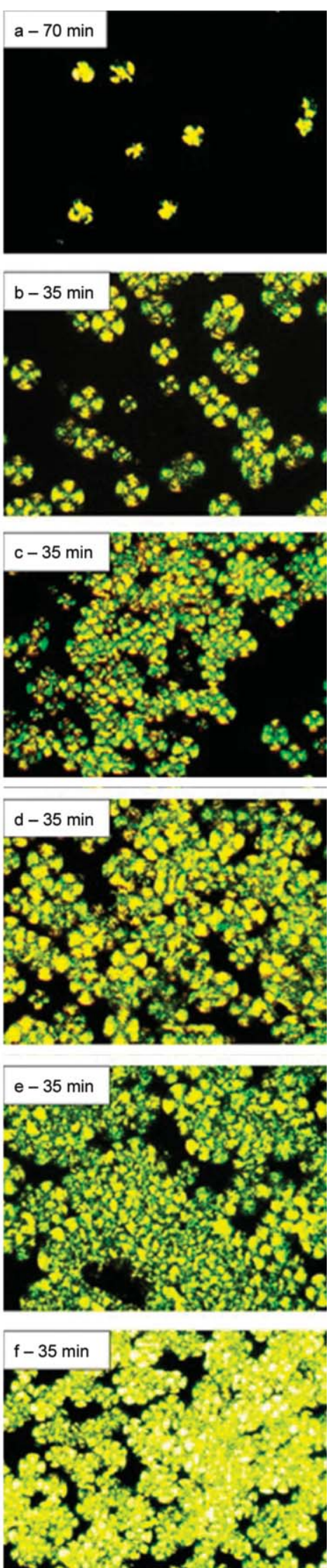

Figure 8. POM photographs of samples at $120^{\circ} \mathrm{C}$. (a) Pure PLGA, (b) $n$-HA/PLGA-5 wt $\%$, (c) Co-HA (10 wt $\left.\%\right) /$ PLGA-5 wt \%, (d) Co-HA (20 wt \%)/PLGA-5 wt\%, (e) Bl-HA (10 wt\%)/PLGA-5 wt\%, (f) Bl-HA(20 wt \%)/PLGA$5 \mathrm{wt} \%$. 
method was evidently better than the co-precipitation method.

Commonly, the larger size of spherulites would be brought about more defects of materials, and the performance of materials would be worse, while the smaller size of the spherulite would make the performance of materials better. For B1-HA (20 wt)/ PLGA- $5 \mathrm{wt} \%$ nanocomposites, the numbers of crystal nuclei formed were more and denser. It took less time for the material to crystallize completely, so the spherulite size was limited. As a result, there were fewer defects in the material and its performance would be improved. Maybe that was the reason for the best mechanical property for B1-HA $(20 \mathrm{wt}) /$ PLGA-5 wt\% nanocomposites.

\subsubsection{Thermal properties}

Figure 9 showed the DSC curves of pure PLGA and four $n$-HA/PLGA composites, and their thermal property data were calculated and given in Table 2 . We could find that the glass transition temperature $\left(T_{\mathrm{g}}\right)$ and the melting temperature $\left(T_{\mathrm{m}}\right)$ of four HA/PLGA composites were higher than that of pure PLGA. Moreover, $T_{\mathrm{g}}$ and $T_{\mathrm{m}}$ of the Bl-HA (20 wt $\left.\%\right) /$ PLGA was higher than that of the Co-HA $(20 \mathrm{wt} \%) /$ PLGA composite, and it could be seen that the more inorganic components in the filler were, the greater increase of $T_{\mathrm{g}}$ and $T_{\mathrm{m}}$ was. The possible reason was that 12-hydroxystearic acid was more conducive to the combination of the interface of $n$-HA and PLGA matrix. However, the melting enthalpy $(\Delta \mathrm{Hm})$ and relative crystallinity $\left(X_{\mathrm{c}}\right)$ of Co-HA $(20 \mathrm{wt} \%) / \mathrm{PLGA}$ was higher than that of Bl-HA (20 wt\%)/PLGA composite. The cause might be that a large part of the increase in crystallinity was due to the peeled organic components from fillers, rather than HA particles.

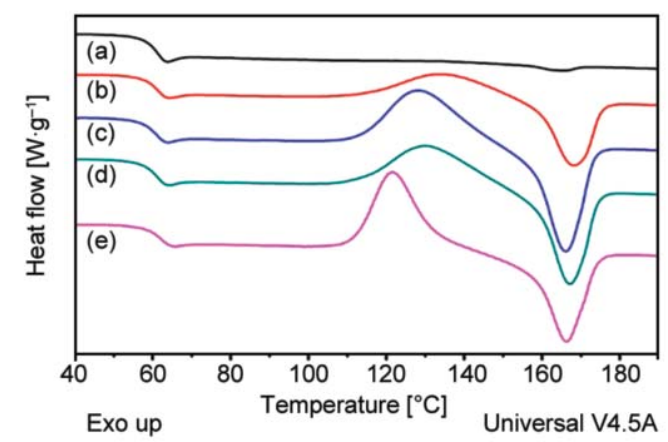

Figure 9. DSC thermograms of (a) pure PLGA, (b) $n-\mathrm{HA} /$ PLGA-5 wt \%,(c) Co-HA (20 wt \%)/PLGA-5 wt $\%$, (d) B1-HA (20 wt $\%) /$ PLGA-5 wt $\%$, (e) B1-HA (20 wt $\%) /$ PLGA-10 wt $\%$.
Table. 2. Thermal properties of composites determined by DSC.

\begin{tabular}{|l|c|c|c|c|}
\hline \multicolumn{1}{|c|}{ Samples } & $\begin{array}{c}\boldsymbol{T}_{\mathbf{g}} \\
{\left[{ }^{\circ} \mathbf{C}\right]}\end{array}$ & $\begin{array}{c}\boldsymbol{T}_{\mathbf{m}} \\
{\left[{ }^{\circ} \mathbf{C}\right]}\end{array}$ & $\begin{array}{c}\Delta \boldsymbol{H}_{\mathbf{m}} \\
{[\mathbf{J} / \mathbf{g}]}\end{array}$ & $\begin{array}{c}\boldsymbol{X}_{\mathbf{c}} \\
{[\mathbf{\%}]}\end{array}$ \\
\hline PLGA & 60.69 & 165.09 & 1.806 & 2.142 \\
\hline$n$-HA/PLGA & 61.49 & 167.98 & 16.860 & 18.940 \\
\hline Co-HA $(20 \mathrm{wt} \%) /$ PLGA-5 $\mathrm{wt} \%$ & 61.16 & 165.92 & 28.160 & 31.640 \\
\hline Bl-HA $(20 \mathrm{wt} \%) /$ PLGA-5 $\mathrm{wt} \%$ & 61.32 & 167.40 & 24.420 & 27.430 \\
\hline Bl-HA $(20 \mathrm{wt} \%) /$ PLGA-10 $\mathrm{wt} \%$ & 62.31 & 166.54 & 27.040 & 32.060 \\
\hline
\end{tabular}

Thus, the improvement of mechanical property was also not obvious, because a large number of organic components reduced the reinforcing effect of fillers on polymers [35].

\subsubsection{Dynamic mechanical property.}

The DMA energy storage modulus $\left(E^{\prime}\right)$ curves and the loss factor $(\tan \delta)$ curves of pure PLGA, $n$-HA/ PLGA, Co-HA (20 wt\%)/PLGA and Bl-HA Bl-HA $(20 \mathrm{wt} \%) /$ PLGA composites were shown in the Figure 10 . According to the curves of $E^{\prime}$, at the low-temperature region, we could see that the $E^{\prime}$ of all the samples decreased slightly with the increase of temperature, and the $E^{\prime}$ decreased sharply at the temperature range of $50-70^{\circ} \mathrm{C}$. This was because the glass transition of all samples occurred with the increase in temperature. Meanwhile, the addition of $n$-HA, Co-HA (20 wt $\%$ ) or Bl-HA (20 wt\%) obviously improved the storage modulus of PLGA. The cause was that the rigid interface would be introduced when the nanoparticles were combined with the polymer matrix, and the rigid interface would absorb more energy and increase the $E^{\prime}$ of the nanocomposites when the materials were broken and damaged. Besides, the $E^{\prime}$ of B1-HA (20 wt $\%$ )/PLGA-5 wt $\%$ composite was higher than that of Co-HA (20 wt $\%) /$ PLGA- $5 \mathrm{wt} \%$ composite. This was because the Bl-HA (20 wt\%) nanoparticles had the best dispersion and interfacial adhesion in PLGA matrix than Co-HA (20 wt $\%$ ) and unmodified $n$-HA [36].

On the other hand, the $\tan \delta$ curves of all samples showed an obvious peak in Figure 10, which was corresponded to the glass transition of the samples. Based on the curve, it could be seen that the significant peak position of the $\tan \delta$ curves of each composite had a small movement to the high-temperature direction with the addition of HA, which indicated that the $T_{\mathrm{g}}$ of the three $n$-HA/PLGA nanocomposites was slightly higher than that of pure PLGA. This was because the addition of HA restricted the mobility of PLGA chain to a certain degree. Additionally, the $T_{\mathrm{g}}$ of the three 

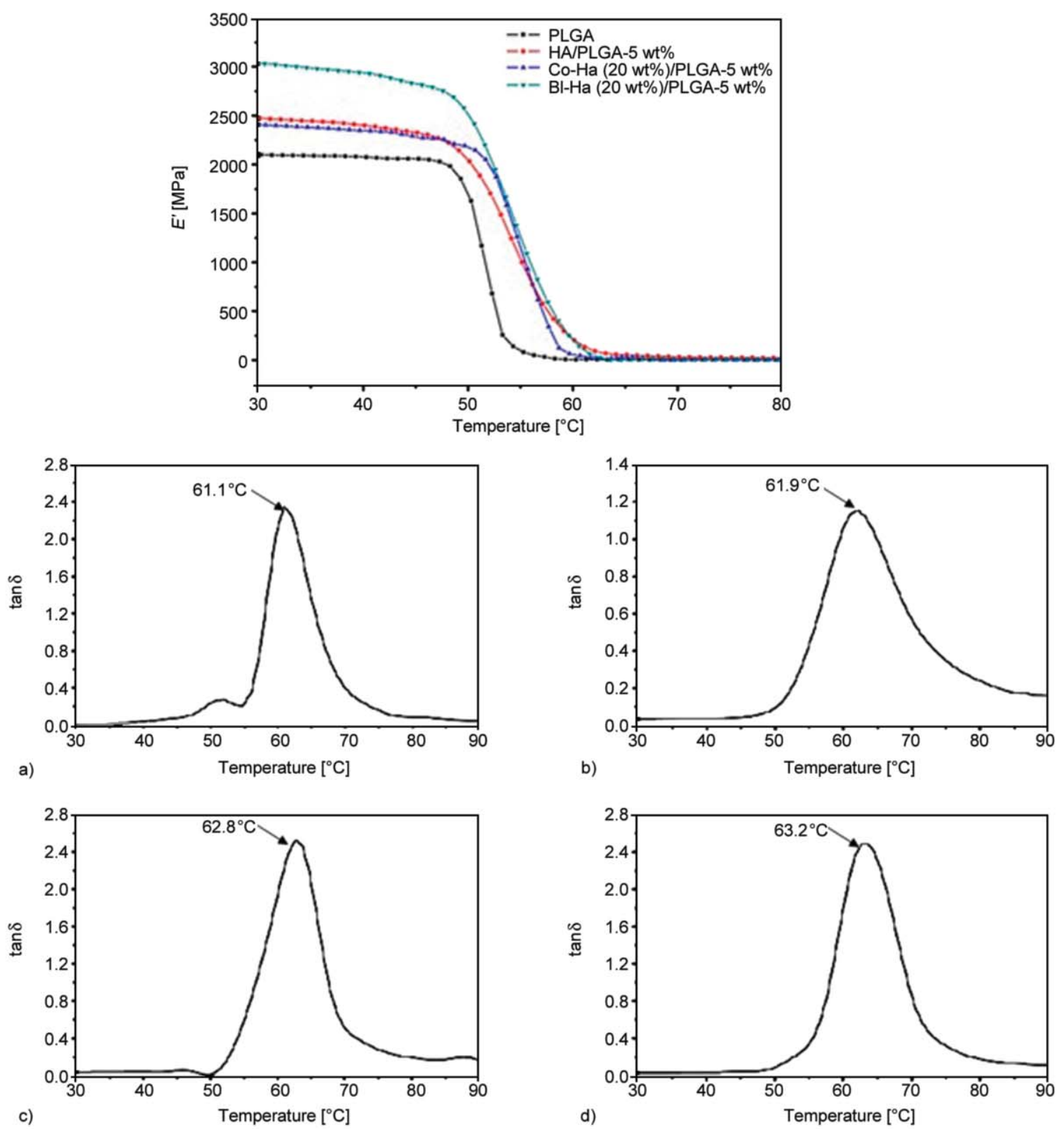

Figure 10. Storage modulus $\left(E^{\prime}\right)$ versus temperature of samples. (a) Pure PLGA, (b) $n$-HA/PLGA-5 wt $\%$, (c) Co-HA (20 wt $\%) /$ PLGA-5 wt $\%$, (d) Bl-HA (20 wt \%)/PLGA-5 wt $\%$.

$n$-HA/PLGA composites obeyed the change order as Bl-HA $(20 \mathrm{wt} \%) / \mathrm{PLGA}-5 \mathrm{wt} \%>\mathrm{Co}-\mathrm{HA}(20 \mathrm{wt} \%) / \mathrm{P}$ LGA-5 wt $\%>n$-HA/ PLGA-5 wt $\%$, which also indicated that the Bl-HA $(20 \mathrm{wt} \%)$ had the best dispersion and interfacial adhesion in PLGA matrix than Co-HA $(20 \mathrm{wt} \%)$, and the result was in accord with the previous discussion, which further explained the reason for the enhanced mechanical property.

\subsection{Effect of BL-HA on cell biocompatibility of PLGA}

\subsubsection{MTT assay}

Figure 11 gave the OD values with culture time. It could be seen that the OD values of the composite samples were significantly higher than that of pure PLGA at 1, 2 and 3 days. The OD values of BL-HA/ PLGA-5 wt $\%$ and BL-HA/PLGA-10wt $\%$ were slightly higher than $n$-HA/PLGA after cultured for 3 days. Besides, the higher the content of BL-HA in composite materials was, the higher the OD value of the sample was. It could be concluded that the addition of BL-HA was favorable to improve the cell biocompatibility of PLGA.

\subsubsection{In vitro cell attachment}

The fluorescence pictures of cells cultured on pure PLGA, $n$-HA/PLGA- 5 wt $\%$, BL-HA/PLGA- 5 wt $\%$ and BL-HA/PLGA- $10 \mathrm{wt} \%$ for 1,2 and 3 days were 
also shown in Figure 11. According to the fluorescence pictures, it could be found that the adhered cells numbers significantly increased with the prolonging of time. Similarly, the cell density on the surface of the sample was accord with the order of BL-HA/PLGA-10 wt $\%>$ BL-HA/PLGA- $5 \mathrm{wt} \%>$ $n$-HA/PLGA-5 wt $\%>$ PLGA, which further demonstrated the BL-HA surface-modified with 12-hydroxystearic acid was nontoxic, and the result was consistent with the MTT assay result.

\section{Conclusions}

In conclusion, 12-hydroxystearic acid was used to surface-modify $n$-HA by co-precipitation or blending method. The results showed that both of the methods ensured 12-hydroxystearic acid was successfully grafted on the $n$-HA, and the blending method confirmed 12-hydroxystearic acid was grafted on the surface of Bl-HA, which endowed $n$-HA with better dispersion in hydrophobic solvents, while the co-precipitation method was more advantageous to obtain

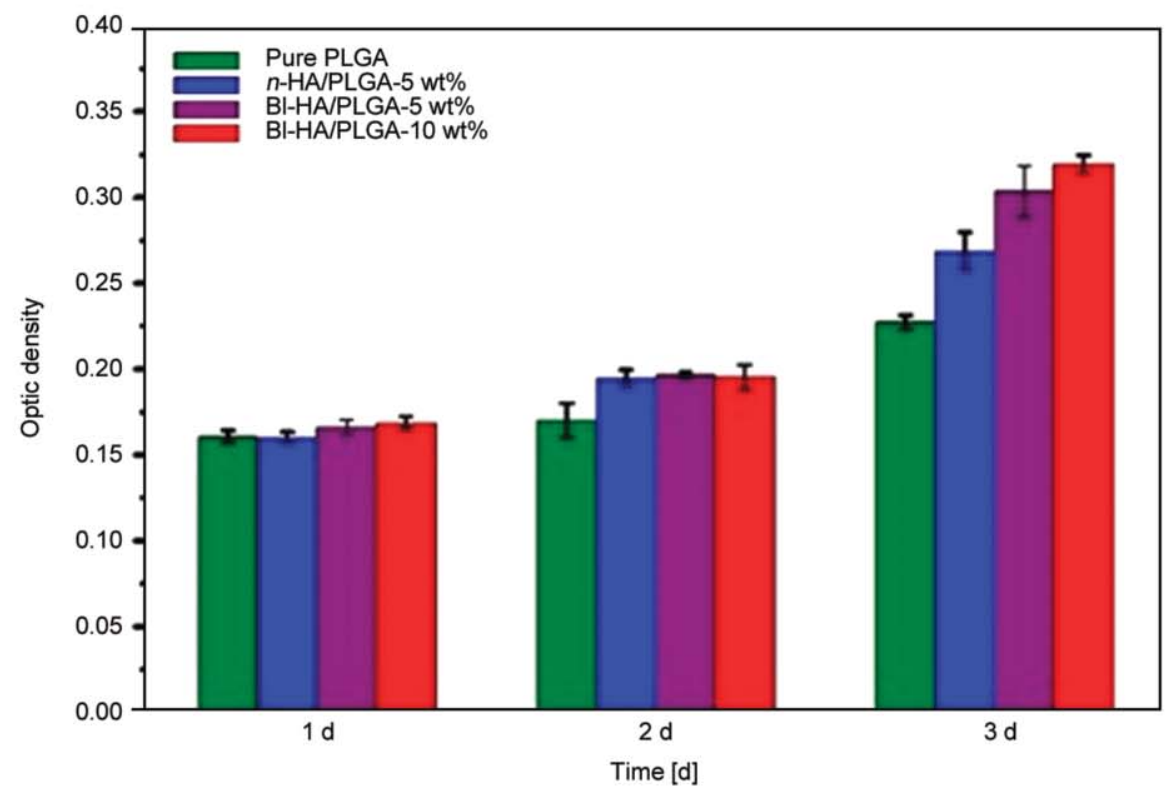

a)
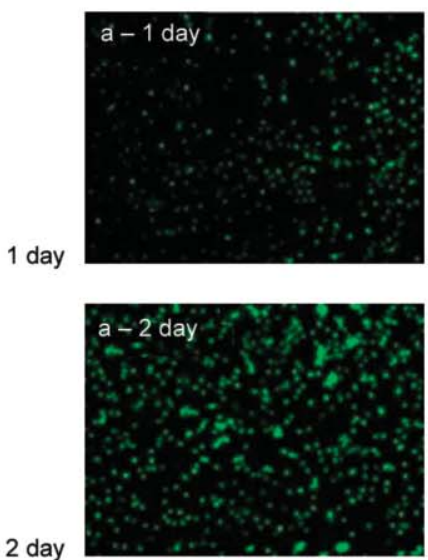

2 day

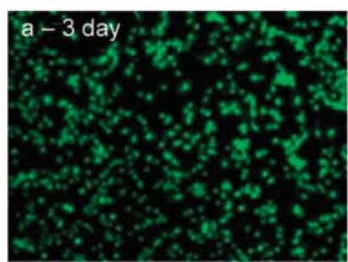

b)
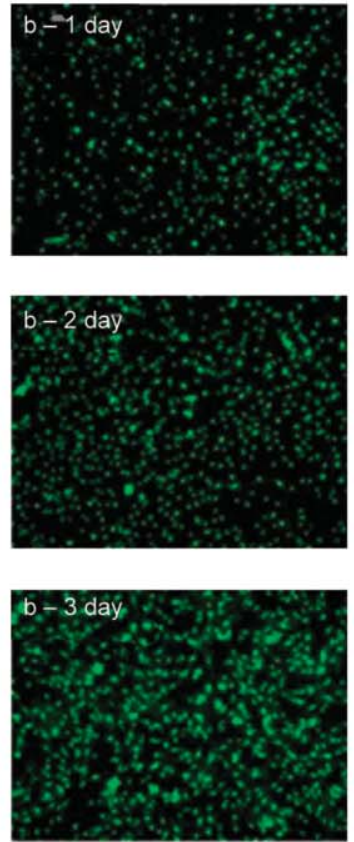

c)
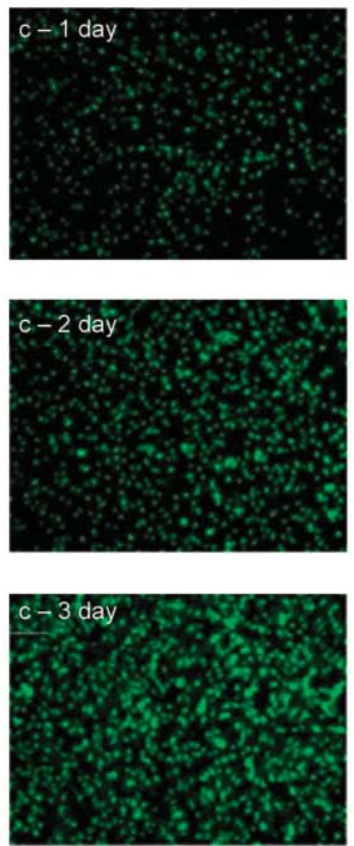

d)
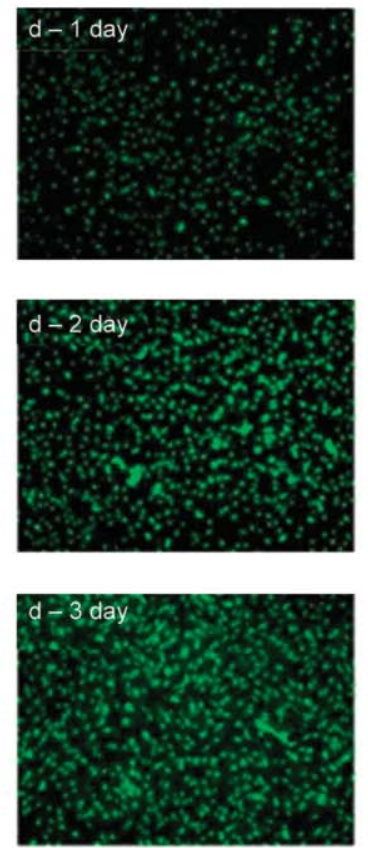

Figure 11. The absorption coefficient of samples by MTT method and fluorescence picture of samples. (a) PLGA, (b) $n$-HA/PLGA-5 wt\%, (c) BL-HA/PLGA-5 wt\%, (d) BL-HA/PLGA-10 wt \%. (The magnificítion was 40 times). 
higher grafting amount of 12-hydroxystearic acid, but most of 12-hydroxystearic acid was effectively incorporated into lattice of Co-HA, which was not conducive for the dispersion of $n$-HA. Correspondingly, Bl-HA displayed better mechanical enhancement for PLGA than Co-HA did. Especially, when the addition amount of Bl-HA (20 wt $\%$ ) was $5 \mathrm{wt} \%$, the tensile strength of the corresponding PLGAbased composite was $23.81 \%$ higher than that of pure PLGA. Additionally, the in vitro cell culture experimental results indicated that B1-HA endowed PLGA with better cell biocompatibility, and the biocompatibility was improved with the addition amount of Bl-HA. Therefore, the study suggested that $n$-HA surface-modified with 12-hydroxystearic acid by the blending method was a new strategy to obtain $n$ HA/PLGA composite, aimed to be used as bone repair materials in the future.

\section{Acknowledgements}

The authors would like to acknowledge the support of the Science and technology project of Changsha (kq1907132), the Innovation Platform Open Found of Hunan Provincial Education Department (Grant No.17K055), Opening Found of Key Laboratory of Chemical Biology \& Traditional Chinese Medicine Research (Ministry of Education of China), Hunan Normal University (No. KLCBTCMR201812) and Hunan Engineering Laboratory for Preparation Technology of Poly(vinyl alcohol) Fiber Material, Huaihua University (Grant HGY201812).

\section{References}

[1] Zhang H. L.: Biomimetic synthesis of poly(lactic-coglycolic acid)/multi-walled carbon nanotubes/apatite composite membranes. Express Polymer Letters, 8, 620-628 (2012).

https://doi.org/10.3144/expresspolymlett.2012.66

[2] Oborná J., Mravcová L., Michlovská L., Vojtová L., Vávrová M.: The effect of PLGA-PEG-PLGA modification on the sol-gel transition and degradation properties. Express Polymer Letters, 10, 361-372 (2016). https://doi.org/10.3144/expresspolymlett.2016.34

[3] Zhou P., Cheng X., Xia Y., Wang P., Zou K., Xu S., Du $\mathrm{J} .:$ Organic/inorganic composite membranes based on poly(L-lactic-co-glycolic acid) and mesoporous silica for effective bone tissue engineering. ACS Applied Materials and Interfaces, 6, 20895-20903 (2014). https://doi.org/10.1021/am505493j

[4] Haider A., Gupta K. C., Kang I-K.: Morphological effects of HA on the cell compatibility of electrospun HA/PLGA composite nanofiber scaffolds. Biomed Research International, 2014, 308306/1-308306/11 (2014). https://doi.org/10.1155/2014/308306
[5] Bundela H., Bajpai A. K.: Designing of hydroxyapatitegelatin based porous matrix as bone substitute: correlation with biocompatibility aspects. Express Polymer Letters, 2, 201-213 (2008).

https://doi.org/10.3144/expresspolymlett.2008.25

[6] Xia X., Chen J., Shen J., Huang D., Duan P., Zou G.: Synthesis of hollow structural hydroxyapatite with different morphologies using calcium carbonate as hard template. Advanced Powder Technology, 29, 15621570 (2018).

https://doi.org/10.1016/j.apt.2018.03.021

[7] Ruphuy G., Saralegi A., Lopes J. C., Dias M. M., Barreiro M. F.: Spray drying as a viable process to produce nano-hydroxyapatite/chitosan ( $n$-HAp/CS) hybrid microparticles mimicking bone composition. Advanced Powder Technology, 27, 575-583 (2016).

https://doi.org/10.1016/j.apt.2016.02.010

[8] Liu Z., Chen Y., Ding W., Zhang C.: Filling behavior, morphology evolution and crystallization behavior of microinjection molded poly(lactic acid)/hydroxyapatite nanocomposites. Composites Part A: Applied Science and Manufacturing, 72, 85-95 (2015).

https://doi.org/10.1016/j.compositesa.2015.02.002

[9] Nagata F., Miyajima T., Kato K.: Preparation of phylloquinone-loaded poly(lactic acid)/hydroxyapatite coreshell particles and their drug release behavior. Advanced Powder Technology, 27, 903-907 (2016). https://doi.org/10.1016/j.apt.2016.02.007

[10] Li H., Zheng Q., Xiao Y., Feng J., Shi Z., Pan Z.: Rat cartilage repair using nanophase PLGA/HA composite and mesenchymal stem cells. Journal of Bioactive and Compatible Polymers, 24, 83-99 (2009). https://doi.org/10.1177/0883911508100655

[11] Petricca S. E., Marra K. G., Kumta P. N.: Chemical synthesis of poly(lactic-co-glycolic acid)/hydroxyapatite composites for orthopaedic applications. Acta Biomaterialia, 2, 277-286 (2006).

https://doi.org/10.1016/j.actbio.2005.12.004

[12] Shi X., Wang Y., Ren L., Gong Y., Wang D-A.: Enhancing alendronate release from a novel PLGA/hydroxyapatite microspheric system for bone repairing applications. Pharmaceutical Research, 26, 422-430 (2009). https://doi.org/10.1007/s11095-008-9759-0

[13] Hong Z., Zhang P., Liu A., Chen L., Chen X., Jing X.: Composites of poly(lactide-co-glycolide) and the surface modified carbonated hydroxyapatite nanoparticles. Journal of Biomedical Materials Research Part A, 8, 1515-1522 (2007). https://doi.org/10.1002/jbm.a.31038

[14] Li J., Lu X. L., Zheng Y. F.: Effect of surface modified hydroxyapatite on the tensile property improvement of HA/PLA composite. Applied Surface Science, 255, 494-497 (2008). https://doi.org/10.1016/j.apsusc.2008.06.067 
[15] Akindoyo O., Beg M. D. H., Ghazali S., Heim H. P., Feldmann M.: Effects of surface modification on dispersion, mechanical, thermal and dynamic mechanical properties of injection molded PLA-hydroxyapatite composites. Composites Part A: Applied Science and Manufacturing, 103, 96-105 (2017).

https://doi.org/10.1016/j.compositesa.2017.09.013

[16] Diao H., Si Y., Zhu A., Ji L., Shi H.: Surface modified nano-hydroxyapatite/poly(lactide acid) composite and its osteocyte compatibility. Materials Science and Engineering C, 32, 1796-1801 (2012).

https://doi.org/10.1016/j.msec.2012.04.065

[17] Wang Y., Zhang X., Yan J., Xiao Y., Lang M.: Surface modification of hydroxyapatite with poly(methyl methacrylate) via surface-initiated ATRP. Applied Surface Science, 257, 6233-6238 (2011).

https://doi.org/10.1016/j.apsusc.2011.02.045

[18] Fan R. R., Zhou L. X., Song W., Li D. X., Zhang D. M., Ye R., Zheng Y., Guo G.: Preparation and properties of $g$-TTCP/PBS nanocomposites and its in vitro biocompatibility assay. International Journal of Biological Macromolecules, 59, 227-234 (2013).

https://doi.org/10.1016/j.ijbiomac.2013.04.051

[19] Fan R., Deng X., Zhou L., Gao X., Fan M., Wang Y., Guo G.: Injectable thermosensitive hydrogel composite with surface-functionalized calcium phosphate as raw materials. International Journal of Nanomedicine, 9, 615-626 (2014).

https://doi.org/10.2147/IJN.S52689

[20] Jiang L. X., Jiang L. Y., Xu L. J., Han C. T., Xiong C. D.: Effect of a new surface-grafting method for nanohydroxyapatite on the dispersion and the mechanical enhancement for poly(lactide-co-glycolide). Express Polymer Letters, 8, 133-141 (2014).

https://doi.org/10.3144/expresspolymlett.2014.16

[21] Jiang L., Xiong C., Chen D., Jiang L., Pang X.: Effect of $n$-HA with different surface-modified on the properties of $n$-HA/PLGA composite. Applied Surface Science, 259, 72-78 (2012).

https://doi.org/10.1016/j.apsusc.2012.06.091

[22] Ding H., Jiang L., Ma B., Su S.: Preparation of a highly dispersed nanohydroxyapatite by a new surface-modification strategy used as a reinforcing filler for poly(lactic-co-glycolide). Industrial and Engineering Chemistry Research, 57, 17119-17128 (2018).

https://doi.org/10.1021/acs.iecr.8b03258

[23] Nakagawa M., Kawai T.: Tuning gel-sol transition behavior of a hydrogel based on 12-hydroxystearic acid and a long-chain amidoamine derivative. Bulletin of the Chemical Society of Japan. 92, 435-440 (2019). https://doi.org/10.1246/bcsj.20180337

[24] Gordon R., Stober S. T., Abrams C. F.: Aggregation of 12-hydroxystearic acid and its lithium salt in hexane: molecular dynamics simulations. Journal of Physical Chemistry B. 120, 7164-7173 (2016).

https://doi.org/10.1021/acs.jpcb.6b04193
[25] Minh D. P., Tran N. D., Nzihou A., Sharrock P.: Onestep synthesis of calcium hydroxyapatite from calcium carbonate and orthophosphoric acid under moderate conditions. Industrial and Engineering Chemistry Research, 52, 1439-1447 (2013).

https://doi.org/10.1021/ie302422d

[26] Li Y., de Groot K., de Wijn J., Klein C. P. A. T., Meer S. V. D.: Morphology and composition of nanograde calcium phosphate needle-like crystals formed by simple hydrothermal treatment. Journal of Materials Science-Materials in Medicine, 5, 326-331 (1994). https://doi.org/10.1007/bf00058956

[27] Bakan F., Laçin O., Sarac H.: A novel low temperature sol-gel synthesis process for thermally stable nano crystalline hydroxyapatite. Powder Technology, 233, 295302 (2013).

https://doi.org/10.1016/j.powtec.2012.08.030

[28] Wu H., Pang D., Ma C., Li Q., Xiong C.: Composites of hydroxyapatite whiskers/poly(L-lactide-co-glycolide) with high tensile plasticity. Journal of Macromolecular Science Part B: Physics, 51, 1242-1255 (2011). https://doi.org/10.1080/00222348.2011.627824

[29] Zhang B-J., He L., Han Z-W., Li X-G., Zhi W., Zheng W., Mu Y-D., Weng J.: Enhanced osteogenesis of multilayered pore-closed microsphere-immobilized hydroxyapatite scaffold via sequential delivery of osteogenic growth peptide and BMP-2. Journal of Materials Chemistry B, 3, 6897-6904 (2015).

https://doi.org/10.1039/C7TB01970J

[30] Yuan X., Zhu B., Tong G., Su Y., Zhu X.: Wet-chemical synthesis of Mg-doped hydroxyapatite nanoparticles by step reaction and ion exchange processes. Journal of Materials Chemistry B, 1, 6551-6559 (2011). https://doi.org/10.1039/c3tb21315c

[31] Sheikh F. A., Kanjwal M. A., Macossay J., Barakat N. A. M., Kim H. Y.: A simple approach for synthesis, characterization and bioactivity of bovine bones to fabricate the polyurethane nanofiber containing hydroxyapatite nanoparticle. Express Polymer Letters, 6, 41-53 (2012). https://doi.org/10.3144/expresspolymlett.2012.5

[32] Yi W-J., Li L-J., He H., Hao Z., Liu B., Shen Y., Chao Z-S.: Poly(L-lactide)/cyclodextrin/citrate networks modified hydroxyapatite and its role as filler in the promotion to the properties of poly(L-lactide) biomaterials. Polymer, 145, 1-10 (2018).

https://doi.org/10.1016/j.polymer.2018.04.034

[33] Wu S-C., Hsu H-C., Hsu S-K., Tseng C-P., Ho W-F.: Preparation and characterization of hydroxyapatite synthesized from oyster shell powders. Advanced Powder Technology, 28, 1154-1158 (2017). https://doi.org/10.1016/j.apt.2017.02.001

[34] Anwar A., Akbar S.: Continuous microwave assisted flow synthesis and characterization of calcium deficient hydroxyapatite nanorods. Advanced Powder Technology, 29, 1493-1498 (2018). https://doi.org/10.1016/j.apt.2018.03.014 
[35] Yang D-D., Liu W., Zhu H-M., Wu G., Chen S-C., Wang X-L., Wang Y-Z.: Toward super-tough poly(Llactide) via constructing pseudo-cross-link network in toughening phase anchored by stereocomplex crystallites at the interface. ACS Applied Materials and Interfaces 10, 26594-26603 (2018).

https://doi.org/10.1021/acsami.8b06343
[36] Zhang Y., Shen J., Li Q., Pang L., Zhang Q., Xu Z., Yeung K. W. K., Yi C.: Synthesis and characterization of novel hyperbranched polyimides/attapulgite nanocomposites. Composites Part A: Applied Science and Manufacturing, 55, 161-168 (2013).

https://doi.org/10.1016/j.compositesa.2013.08.014 